\title{
Homogeneous MMR Deficiency Throughout the Entire Tumor Mass Occurs in a Subset of Colorectal Neuroendocrine Carcinomas
}

\author{
Christoph Fraune $^{1} \cdot$ Ronald Simon $^{1} \cdot$ Claudia Hube-Magg $^{1} \cdot$ Georgia Makrypidi-Fraune $^{1} \cdot$ Martina Kluth ${ }^{1}$. \\ Franziska Büscheck ${ }^{1}$. Tania Amin ${ }^{3}$. Fabrice Viol ${ }^{3}$. Wilfrid Fehrle ${ }^{1}$. David Dum ${ }^{1}$ • Doris Höflmayer ${ }^{1}$ Eike Burandt ${ }^{1}$. \\ Till Sebastian Clauditz ${ }^{1}$ - Daniel Perez ${ }^{2}$. Jakob Izbicki ${ }^{2}$. Waldemar Wilczak ${ }^{1}$. Guido Sauter ${ }^{1}$ • Stefan Steurer ${ }^{1}$. \\ Jörg Schrader ${ }^{2,3}$
}

Published online: 6 March 2020

(C) The Author(s) 2020

\begin{abstract}
Neuroendocrine neoplasms comprise a heterogeneous group of tumors, categorized into neuroendocrine tumors (NETs) and neuroendocrine carcinomas (NECs) depending on tumor differentiation. NECs and high-grade NETs (G3) confer a poor prognosis, demanding novel treatment strategies such as immune checkpoint inhibition in tumors with microsatellite instability (MSI). To study any possible intratumoral heterogeneity of MSI, a tissue microarray (TMA) containing 199 NETs and 40 NECs was constructed to screen for MSI using immunohistochemistry (IHC) for the mismatch repair (MMR) proteins MLH1, PMS2, MSH2, and MSH6. Four cases suspicious for MSI were identified. Validation of MSI by repeated IHC on large sections and polymerase chain reaction (PCR)-based analysis using the "Bethesda Panel" confirmed MSI in 3 cecal NECs. One pancreatic NET G3 with MSI-compatible TMA results was MMR intact on large section IHC and microsatellite stable (MSS). The remaining 235 tumors exhibited intact MMR. Protein loss of MLH1/PMS2 was found in two and MSH6 loss in one cancer with MSI. Large section IHC on all available tumor-containing tissue blocks in NECs with MSI did not identify aberrant tumor areas with intact MMR. Our data indicate that MSI is common in colorectal NECs ( 3 out of 10) but highly infrequent in neuroendocrine neoplasms from many other sites. The lack of intratumoral heterogeneity of MMR deficiency suggests early development of MSI during tumorigenesis in a subset of colorectal NECs and indicates that microsatellite status obtained from small biopsies may be representative for the entire cancer mass.
\end{abstract}

Keywords Microsatellite instability $\cdot$ Tissue microarray $\cdot$ Neuroendocrine tumor $\cdot$ Neuroendocrine carcinoma

\section{Introduction}

Neuroendocrine neoplasms occur at various organ sites and comprise a heterogeneous group of epithelial tumors ranging from well-differentiated neuroendocrine tumors (NETs) to poorly differentiated carcinomas, called neuroendocrine

Ronald Simon

R.Simon@uke.de

1 Institute of Pathology, University Medical Center Hamburg-Eppendorf, Martinistr. 52, 20246 Hamburg, Germany

2 General, Visceral and Thoracic Surgery Department and Clinic, University Medical Center Hamburg-Eppendorf, Hamburg, Germany

3 I. Medical Department - Gastroenterology and Hepatology, University Medical Center Hamburg-Eppendorf, Hamburg, Germany carcinomas (NECs). NETs clinically often present as lowgrade malignancies, while NECs behave more aggressively with rapid disease progression and poor long-term survival, demanding for novel treatment options.

Microsatellite instability (MSI) refers to a distinctive pattern of increased mutational load in certain tumors, typically caused by a defective DNA mismatch repair (MMR) apparatus, and is characterized by accumulated length variations of repetitive DNA sequences (microsatellites) throughout the genome. Protein loss of at least one of the major components of the MMR system-MLH1, PMS2, MSH2, or MSH6, which can easily be analyzed by immunohistochemistry (IHC) provides strong indirect evidence for MSI. MSI can also be detected via direct analysis of a predefined panel of DNA microsatellite loci with classic polymerase chain reaction (PCR)-based methods or novel high-throughput molecular techniques [1]. Favorable response rates for immune checkpoint inhibitors in cancers with MSI have dramatically 
increased the clinical request for MSI testing, even in tumor types with low expected rates of MSI. This was paralleled by the 2017 site-agnostic FDA approval of the PD-1 antibody pembrolizumab for advanced cancers with MMR deficiency/ MSI-high.

Data on MSI in neuroendocrine neoplasms are limited. Recent studies have found tumors with MSI among neuroendocrine carcinomas (some combined with a conventional adenocarcinoma component, MINEN) of the stomach, small intestine, and colorectum [2-6]. The few available studies describing MSI in cohorts of NETs are basically limited to pancreatic primaries with reported frequencies between $10 \%$ $(5 / 48)$ and $33 \%(18 / 55)$ by PCR-based methods $[7,8]$. Intratumoral heterogeneity of MSI-a potential strong confounder for molecular based treatments - has been observed in several cancer types, including colorectal cancer [9-13]. However, intratumoral heterogeneity of MSI in neuroendocrine neoplasms has not been evaluated so far.

To systematically assess potential intratumoral heterogeneity of MMR protein expression in neuroendocrine neoplasms with MMR deficiency, a cohort of 239 NETs and NECs was screened on a tissue microarray (TMA) format by IHC, followed by a large section evaluation of cancers suspected for MSI by repeated IHC and PCR analysis.

\section{Material and Methods}

Tissue Microarray A TMA comprising 239 neuroendocrine neoplasms and various control tissues was constructed using one tissue core per tumor from archived material from patients diagnosed with a NET or NEC at the University Medical Center Hamburg-Eppendorf between 2009 and 2018. TMA construction was described earlier [14]. Clinical and pathological information were obtained from the patient's medical records and reports. NET- and NEC-categorization was based on the criteria described in the recent 5 th edition of the WHO classification of tumors of the digestive system, and differentiation between NECs and high-grade (G3) NETs was adopted from Tang et al. [15]. No mixed tumors with an additional non-neuroendocrine tumor component (MINEN) were identified. Utilization of archived diagnostic leftover tissues for manufacturing of TMAs and their analysis for research purposes as well as patient data analysis has been approved by local laws (HmbKHG, §12,1) and by the local ethics committee (Ethics commission Hamburg, WF-049/09). All work has been carried out in compliance with the Helsinki Declaration.

Immunohistochemical Analyses To screen for MSI cancers, freshly taken TMA sections were immunostained on 1 day and in one experiment using an automated immunostainer (Dako/Agilent Autostainer Link 48). Primary antibody specific for MLH1 (clone ES05, mouse), PMS2 (clone EP51, rabbit), MSH2 (clone FE11, mouse), and MSH6 (clone EP49, rabbit) (all Ready-to-Use, all from DAKO, Glostrup, Denmark) was applied for $20 \mathrm{~min}$ (MLH1, MSH2, MSH6) or 30 min (PMS2). Bound antibody was visualized using the EnVision Kit (Dako, Glostrup, Denmark) according to the manufacturer's directions. Tumors were scored as negative (0) when nuclear staining was absent in all captured tumor cells and positive $(+)$ when unequivocal nuclear staining in tumor cells (irrespective of staining intensity or percentage of stained cells) was observed. In spots showing a negative (0) result for the tumor cells, presence (+) or absence (-) of nuclear staining in peritumoral stromal or inflammatory cells was also recorded (internal control). For TMA spots with a staining loss of any MMR protein in tumor cells but not in stromal/inflammatory cells (suspected MSI), IHC was repeated on a corresponding large section of the routinely archived tumor material and PCR analysis was performed. In case of non-interpretable TMA spots (lack of unequivocal tumor tissue or negative ( 0 ) tumor cells accompanied by absence of an internal control $(-)$ ), staining was repeated on a representative large section.

PCR Analysis For all cases with suspected MSI based on TMA screening, a fluorescent PCR-based assay was performed (MSI Analysis System; Promega, Madison, WI), incorporating the five microsatellite loci of the "Bethesda Panel" which includes two mononucleotide repeats (BAT25, BAT26) and three dinucleotides repeats (D2S123, D5S346, and D17S250) [16]. Analysis was based on DNA extracted from tumor tissue that was dissected from a large section of the respective tumor block corresponding to the TMA case and from non-neoplastic control tissue of the patient. Percentage of tumor cells was at least $50 \%$ within the analyzed tissue area. Status of MSI-high was given when at least $2(\geq 40 \%)$ of the markers showed instability (i.e., length variation compared with control tissue) and status of MSI-low if one of the analyzed loci showed instability; otherwise, microsatellite stability (MSS) was assumed.

Evaluation of Cancer Heterogeneity If MSI was confirmed, all available archived tumor-containing tissue blocks were analyzed to search for intratumoral heterogeneity. All together 20 large sections were analyzed for 3 patients with confirmed MMR deficiency.

\section{Results}

TMA Screening and Large Section Validation From 239 neuroendocrine neoplasms, including 199 NETs and 40 NECs of gastroenteropancreatic and pulmonary sites (Table 1), TMA screening obtained interpretable results in 224 (94\%) cases. Tumors were considered interpretable if either unequivocal 
Table 1 Study cohort of neuroendocrine neoplasms separated by anatomic site, tumor type and tumor grade

\begin{tabular}{|c|c|c|c|c|c|c|}
\hline \multirow[t]{2}{*}{ Site } & \multicolumn{3}{|c|}{ NET } & \multicolumn{2}{|c|}{ NEC } & \multirow[t]{2}{*}{ Sum } \\
\hline & G1 & G2 & G3 & $\mathrm{SC}$ & $\mathrm{LC}$ & \\
\hline Esophagus & & & & 1 & 4 & 5 \\
\hline Stomach & 5 & 2 & & & 1 & 8 \\
\hline Duodenum & 2 & 2 & & & & 4 \\
\hline Ampulla Vateri & 1 & & & & & 1 \\
\hline Jejunum & 2 & 1 & & & & 3 \\
\hline Meckel's diverticulum & 1 & 1 & & & & 2 \\
\hline Ileum & 36 & 17 & 1 & & 1 & 55 \\
\hline Appendix & 20 & 2 & & & & 22 \\
\hline Colorectum & 8 & 1 & & 5 & 5 & 19 \\
\hline Pancreas & 28 & 26 & 5 & 1 & 4 & 64 \\
\hline Gall bladder & & 1 & & 3 & 1 & 5 \\
\hline Lung & 12 & 7 & & 2 & 5 & 26 \\
\hline Metastatic* & 6 & 10 & 2 & 5 & 2 & 25 \\
\hline Sum & 121 & $\begin{array}{c}70 \\
199\end{array}$ & 8 & 17 & 23 & 239 \\
\hline
\end{tabular}

*Primary tumor sites include ileum (7), pancreas (2), lung (2), rectum (1), and unknown (CUP; 6) for metastatic NETs and lung (2), appendix (1), and unknown (CUP; 4) for metastatic NECs

loss of staining for at least one of the four MMR proteins MLH1, PMS2, MSH2, or MSH6 with an internal positive control (MMR deficient) or unequivocally retained expression for all 4 MMR proteins (MMR intact) was observed. For noninterpretable TMA cases - due to lack of unequivocal tumor tissue on the TMA spot $(n=15)$ - large section IHC was performed and revealed intact MMR in each cases. Two hundred twenty from the 224 tumors with interpretable results from TMA screening were also MMR intact, resulting in 235 of 239 neuroendocrine neoplasms demonstrating retained expression of all four MMR proteins. The remaining 4 tumors were all high-grade neuroendocrine neoplasms, including one pancreatic NET G3 and 3 colorectal NECs, demonstrating loss of one or two MMR proteins on the TMA accompanied by an adequate internal positive control, and were thus considered suspicious for MSI (Table 2). Representative micrographs from the three cecal NECs with MMR deficiency are shown in Fig. 1.

MSI Validation Large section validation confirmed MMR deficiency in 3 of 4 suspected cases, all representing NECs of the colorectum (Table 2). Two of these cancers were negative for MLH1/PMS2 and one showed isolated protein loss of MSH6. All three were MSI-high by PCR-analysis, were located in the cecum, and demonstrated large cell phenotype. No nonneuroendocrine tumor component was found. Clinicopathological data did not reveal any further clear-cut associations as compared with colorectal NECs with intact
MMR (Table 3). The one tumor with suspected MSI based on TMA screening that turned out MMR intact on large section analysis was a pancreatic NET G3 with strongly attenuated PMS2 immunoreactivity throughout the majority of the tumor, but PMS2 expression was still retained and the other analyzed MMR proteins were inconspicuous. A comparison with the PMS2 staining on a corresponding large section revealed that the TMA spot had unluckily been taken from an area with markedly diminished immunoreactivity (Fig. 2). PCR analysis did not show any instability among the analyzed microsatellite loci (MSS) in this tumor.

MSI Heterogeneity Analysis In the 3 NECs with confirmed MSI, IHC for MLH1, PMS2, MSH2, and MSH6 from all available archived cancer-containing tumor blocks $(n=20)$ revealed consistent MMR protein loss throughout the entire tumor mass. No concurrent tumor areas with intact MMR were found.

\section{Discussion}

A TMA containing 199 NETs and 40 NECs of various primary sites was manufactured for the purpose of this study as a screening tool to identify tumors with MSI among the heterogeneous group of neuroendocrine neoplasms. Detection of rare events is an ideal application for TMAs. For example, earlier studies identified 42 tumors harboring IDH1 mutations by screening 15,531 prostate cancers $(0.3 \%)$ or 43 tumors exhibiting CD117 overexpression in a cohort of 1654 breast carcinomas $(2.6 \%)[17,18]$. We recently also identified MMR deficiency/MSI in 5 tumors in a series of 448 bladder cancers $(1.1 \%)$, in 7 tumors in a series of 200 advanced and/or hormone refractory prostate cancers $(3.5 \%)$, and in 9 tumors in a series of 479 ovarian cancers (1.8\%) (unpublished data). In the present study, only one of the 4 tumors with suspected MMR deficiency/MSI based on TMA screening turned out to be MMR intact on subsequent large section analysis. The discrepant results between TMA and large section IHC were observed in a pancreatic NET G3 and attributable to suboptimal immunoreactivity of major tumor areas, which-for PMS2 - resulted in still faintly detectable staining of stromal cells but negativity of tumor cells on the TMA spot in contrast to unequivocally retained MMR protein expression in cancer cells on large section. This observation may reflect somewhat higher PMS2 expression levels in a subset of stromal cells as compared with cancer cells.

Among the 239 analyzed neuroendocrine neoplasms, MSI was confirmed in 3 cases (1.3\%), all representing NECs of the cecum, suggesting a considerable prevalence of MSI $(30 \%$; 3/10) in colorectal NECs, although this may not reflect the true MSI rate in colorectal NECs due to the small tumor cohort. None of the other primary NECs from different sites of 
Table 2 Summary of IHC and PCR data on neuroendocrine neoplasms with suspected MSI based on TMA screening. Not all of the 5 microsatellite loci of the "Bethesda Panel" were evaluable by PCR for each tumor with MSI; however, status of MSI was still unequivocal in each case

\begin{tabular}{|c|c|c|c|c|c|c|c|c|c|c|c|c|}
\hline \multirow[t]{2}{*}{ Tumor type } & \multicolumn{4}{|c|}{ TMA screening } & \multicolumn{6}{|c|}{ Large section validation } & \multicolumn{2}{|l|}{ Entire tumor } \\
\hline & MLH1 & PMS2 & MSH2 & MSH6 & MLH1 & PMS2 & MSH2 & MSH6 & Status IHC & PCR & $\begin{array}{l}\text { Tumor blocks } \\
(n=)\end{array}$ & MMR pattern \\
\hline $\begin{array}{r}\text { Pancreatic } \\
\text { NET G3 }\end{array}$ & + & - & + & + & + & $\begin{array}{l}+ \\
\quad(\mathrm{w}- \\
\text { eak) }\end{array}$ & + & + & $\begin{array}{l}\text { MMR } \\
\text { intact }\end{array}$ & $\operatorname{MSS}(0 / 5)$ & - & - \\
\hline $\begin{array}{l}\text { Colorectal } \\
\text { NEC }\end{array}$ & - & - & + & + & - & - & + & + & $\begin{array}{l}\text { MMR } \\
\text { deficient }\end{array}$ & $\begin{array}{l}\text { MSI-high } \\
\text { (4/4) }\end{array}$ & 5 & $\begin{array}{l}\text { Homogeneous MMR } \\
\text { deficiency }\end{array}$ \\
\hline $\begin{array}{l}\text { Colorectal } \\
\text { NEC }\end{array}$ & + & + & + & - & + & + & + & - & $\begin{array}{l}\text { MMR } \\
\text { deficient }\end{array}$ & $\begin{array}{l}\text { MSI-high } \\
(3 / 5)\end{array}$ & 7 & $\begin{array}{l}\text { Homogeneous MMR } \\
\text { deficiency }\end{array}$ \\
\hline $\begin{array}{c}\text { Colorectal } \\
\text { NEC }\end{array}$ & - & - & + & + & - & - & + & + & $\begin{array}{l}\text { MMR } \\
\text { deficient }\end{array}$ & $\begin{array}{l}\text { MSI-high } \\
(3 / 3)\end{array}$ & 8 & $\begin{array}{l}\text { Homogeneous MMR } \\
\text { deficiency }\end{array}$ \\
\hline
\end{tabular}

the gastrointestinal tract $(n=15)$ and the lung $(n=7)$ exhibited MSI. These data fit with previous studies reporting particularly high rates of MSI in NECs of the colorectum. Sahnane et al. found MSI in 6 of 37 (16\%), Olevian et al. in 2 of $29(7 \%)$, Furlan et al. in 2 of $21(10 \%)$, and La Rosa et al. in 3 of 35 $(14 \%)$ colorectal NECs $[2,4-6]$. In the study by Sahnane et al. also 4 tumors with MSI were identified among 36 gastric NECs (11\%) [2]. A high frequency of MSI (44\%) based on IHC detection of MMR protein loss was further observed by Pocrnich et al. in a cohort of 18 large cell NECs of the endometrium [19]. In contrast, NECs from other organs have rarely been found to exhibit MSI. Sahnane et al. found only one other tumor with MSI among 16 NECs of the duodenum, esophagus, pancreas, and gall bladder [2].

Taken together, the available data suggest that the prevalence of MSI in NECs is site-dependent and closely related to those organ sites where the exocrine neoplastic counterparts of NECs - adenocarcinomas - are also frequently affected by MSI, such as endometrial, colorectal, and gastric adenocarcinomas. All 3 colorectal NECs with MSI in the present study were located in the cecum, corresponding well to the strong association of MSI in sporadic colorectal adenocarcinomas

P1

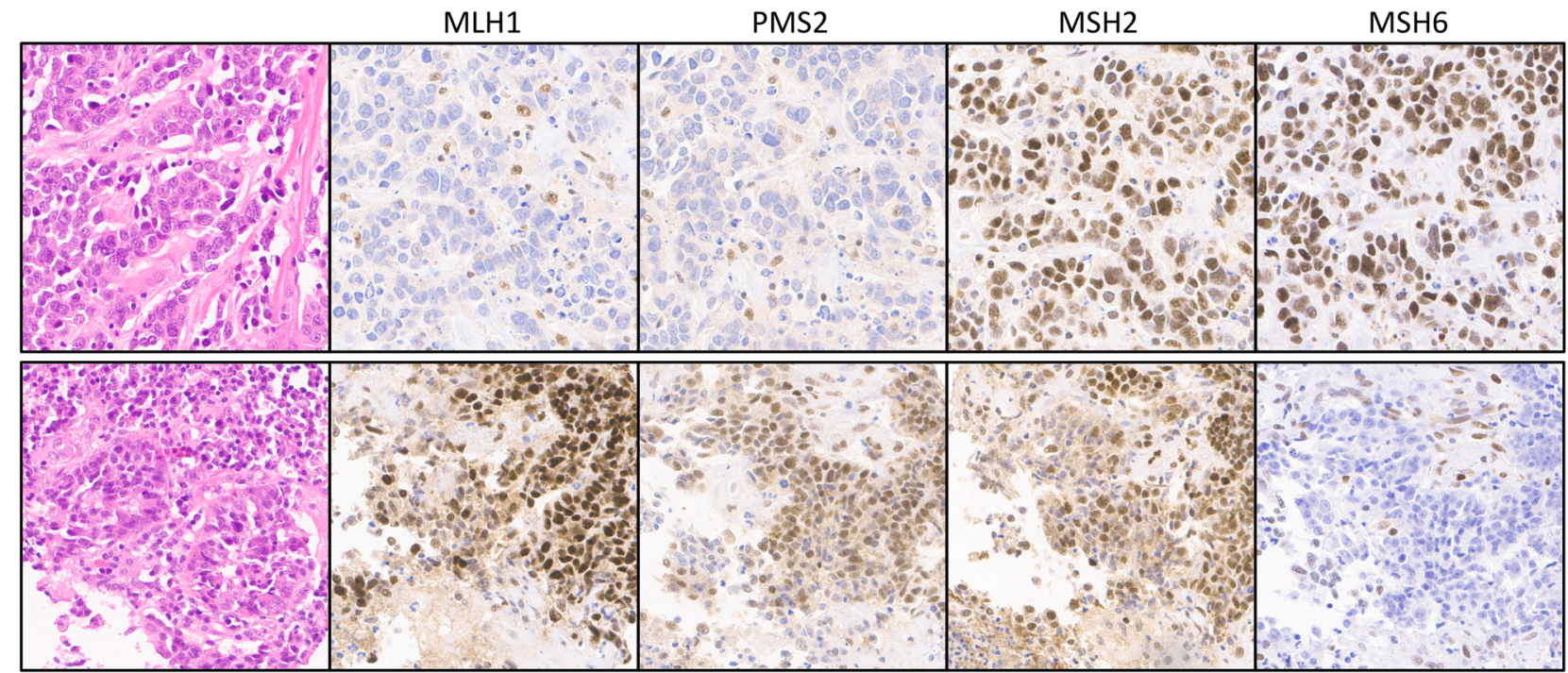

P4

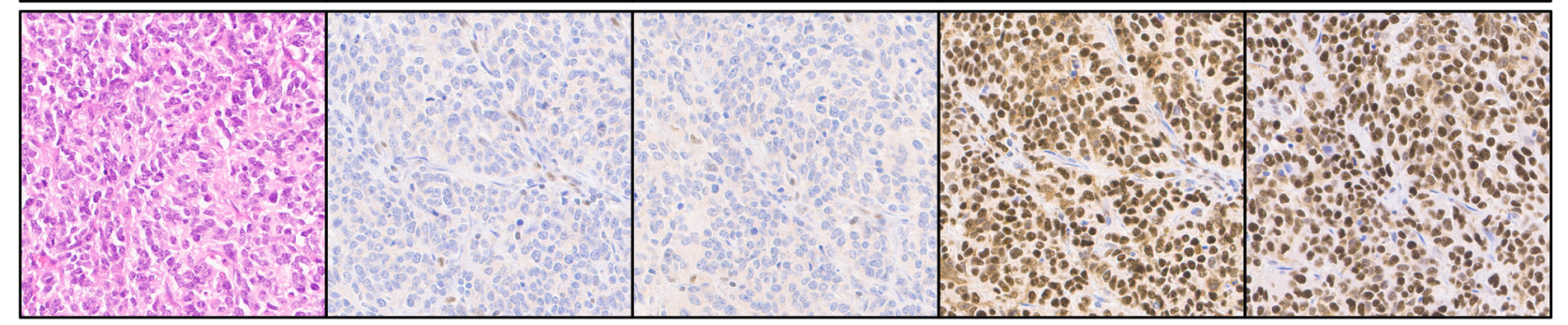

Fig. 1 TMA spots of the three colorectal NEC with MSI. Two cancers showed loss of MLH1/PMS2 and one cancer isolated loss of MSH6 


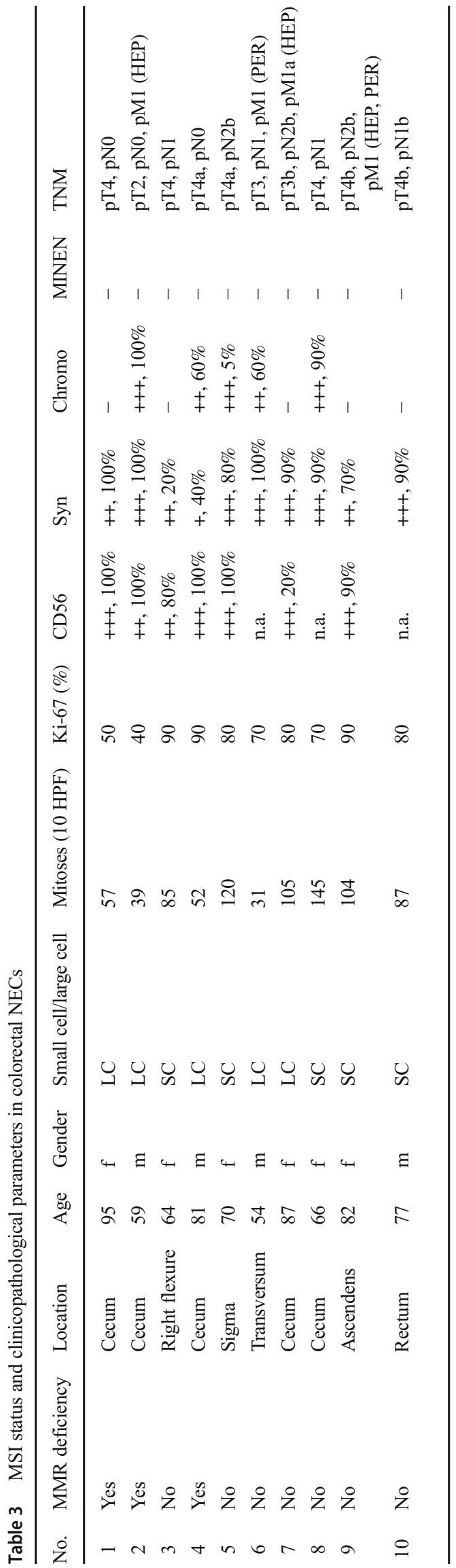

with tumor location in the right colon [20]. A link between MSI in conventional and neuroendocrine carcinomas of distinct organ sites is further supported by several reports of MSI in NECs with concomitant adenocarcinoma components in the affected tumors (MINENs) $[2,4,6]$. The concept of site dependency of MSI in NECs is also supported by the reported absence of MSI-high tumors among 107 small cell lung cancers by Chung et al. [21], paralleling the low frequency of MMR deficiency in non-small cell lung cancer [22-26]. Based on the available data, MSI should be regularly tested in colorectal, gastric, and endometrial NECs. As NECs confer a very poor prognosis and no second line treatment after failure of Cis/Carboplatin and Etoposide has been established [27], MSI testing should be performed during initial diagnosis to avoid unnecessary treatment delay upon progression after first-line treatment. As colorectal NECs have less than 50\% response rate upon Platin-based chemotherapy and an overall survival of less than 9 months, this patient group might in particular benefit from upfront MSI testing and initiation of immune checkpoint inhibitor therapy [27].

In contrast to NECs, none of the 199 NETs exhibited MSI in the present study. That MSI is highly infrequent in NETs fits well with data from earlier studies. MSI was not found in previous studies analyzing 56 rectal [28], 14 small bowel [29], 16 pancreatic [30], 29 gastroenteropancreatic [31], and 38 foregut/midgut [32] as well as 35 pancreatic and 34 small intestinal NETs [33] by PCR. In contrast, two earlier studies described relevant MSI rates in pancreatic NETs [7, 8]. However, as those studies were performed 10 and more years ago, the applied approach to identify or define MSI differs from current standards. House et al. reported MSI in 5 of 48 (10\%) pancreatic NETs using the "Bethesda Panel," but status of MSI was already given when merely the mononucleotide repeat locus BAT- 25 was instable, contrasting the current cutoff requiring instability in $40 \%$ of loci to justify MSI [7]. Mei et al. reported MSI-high, defined as instability of at least 4 loci of an extended panel of 12 microsatellites, in 18 of 55 (33\%) insulinomas [8]. In contrast, all 8 insulinomas among the cohort of 56 pancreatic NETs analyzed in the present study were MMR intact. There are, however, reports describing MMR deficiency in few individual cases of pancreatic NETs in patients with hereditary MMR deficiency (Lynch Syndrome) $[34,35]$.

Evaluation of the MMR status throughout all available cancer-containing tumor blocks revealed homogeneous MMR protein loss in all three NECs with confirmed MSI. This is in agreement with our previous observations of high homogeneity of MSI in prostate [36], ovarian [37], and bladder cancer (unpublished data). Overall, these data may suggest that MMR inactivation generally occurs early in tumorigenesis. Regarding treatment purposes, homogeneity of MSI reduces the risk that molecular parameters obtained from small biopsies may not be representative for the entire cancer mass, 


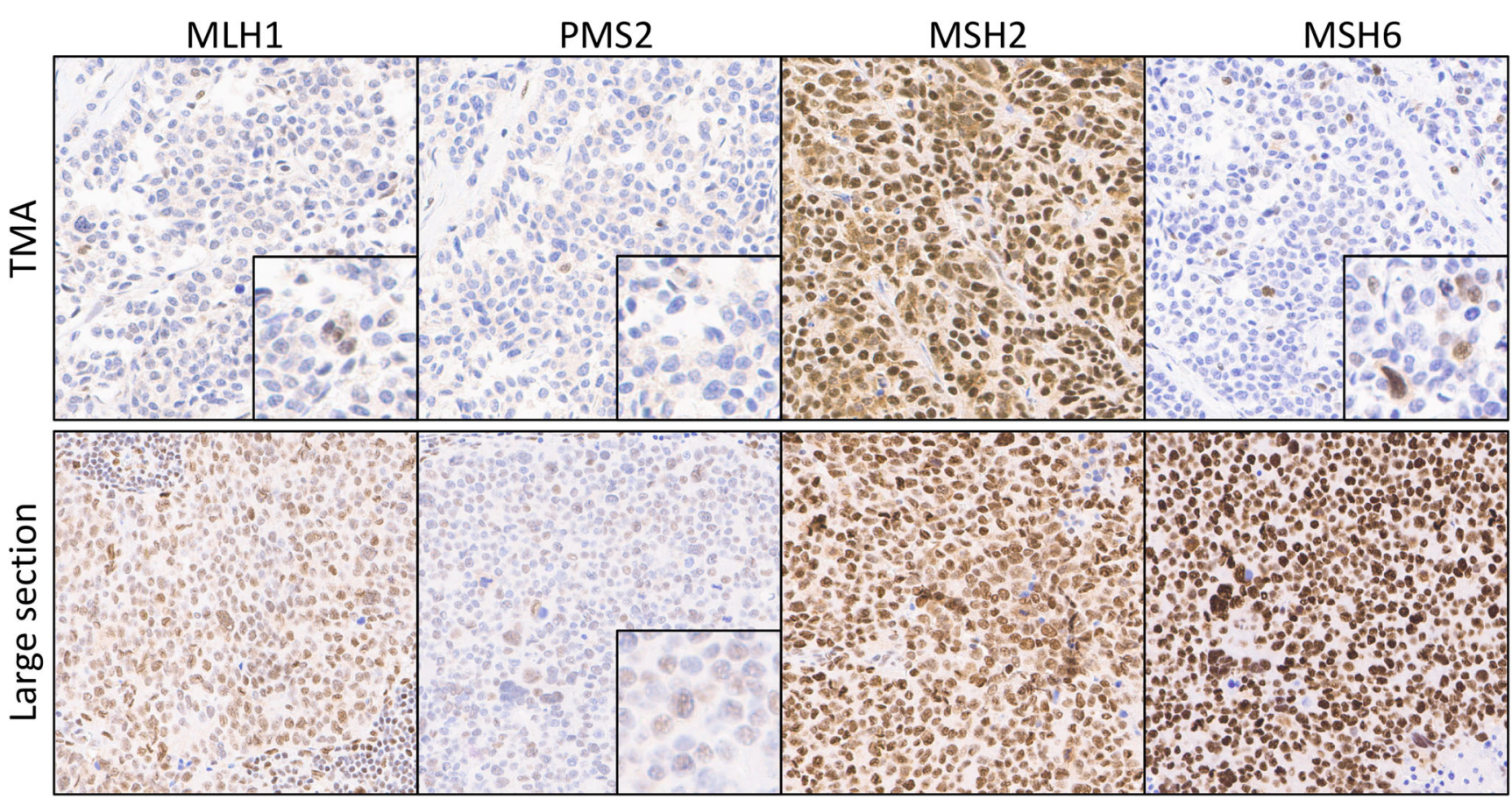

Fig. 2 Suspected MMR deficiency by TMA screening in a NET with intact MMR. For one pancreatic NET G3, TMA immunohistochemistry was interpreted as isolated PMS2 loss but repeated large section IHC showed intact MMR and PCR revealed microsatellite stability (MSS)

a potential strong confounder for individualized therapies. It is a limitation of our study that results for all tumors with intact MMR were derived from TMA cores and it cannot be completely ruled out that a tumor with heterogeneous MMR/MSI status has been missed among this group because a MMR-deficient tumor area has not been represented on the respective TMA spot.

PCR analysis revealed MSI-high in all 3 cases of MMR deficiency. Although the number of cases is too small to draw major conclusions, the high concordance between IHC and PCR results is not surprising. The "Bethesda Panel," a selection of 5 specific mono- and dinucleotide repeats, has been developed based on data derived from colorectal cancers [16]. As different microsatellite loci are not equally affected by frameshifts in the state of MSI due to an association between transcriptional activity and the occurrence of instability in individual repeat loci $[38,39]$, a tissue-dependent pattern of MSI is conceivable. Loci typically demonstrating instability in colorectal adenocarcinomas with MSI, i.e., the loci covered by the "Bethesda Panel," may be affected with comparable frequency in colorectal NECs exhibiting MSI, just as both tumor types certainly show genetic overlap due to their shared origin from large bowel mucosa.

In summary, the detection of MSI in 3 of 10 colorectal NECs but not in other neuroendocrine neoplasm suggests that MSI affects NECs of the colorectum in a relevant manner, similar to colorectal adenocarcinomas. In contrast, MSI is highly infrequent in NETs irrespective of tumor site. The observed complete homogeneity of MMR deficiency indicates that the use of minor biopsy samples should result in highly representative data and hints towards MSI as an early event in tumorigenesis. Testing for MSI early in the course of disease might open novel treatment options for colorectal NECs.

Acknowledgments We are grateful to Melanie Witt, Maren Eisenberg, Gabi Rieck, Sina Dietrich, and Jana Hagemann for excellent technical assistance.

Author Contributions CF, RS, GS, WF, JS: contributed to conception, design, data collection, data analysis and manuscript writing.

WF: data analysis and manuscript writing.

DH, FB, EB, TC, DP, JI: conception and design, collection of samples. CF, CHM, TA, FV, GMF, MK: collection and data analysis.

WW, GS, SS: study supervision.

Funding Information Open Access funding provided by Projekt DEAL.

\section{Compliance with Ethical Standards}

Statement of Ethics The usage of archived diagnostic left-over tissues for manufacturing of TMAs and their analysis for research purposes as well as patient data analysis has been approved by local laws (HmbKHG, $\S 12,1$ ) and by the local ethics committee (Ethics commission Hamburg, WF-049/09). All work has been carried out in compliance with the Helsinki Declaration.

Conflict of Interest The authors declare that they have no conflicts of interest.

Open Access This article is licensed under a Creative Commons Attribution 4.0 International License, which permits use, sharing, adaptation, distribution and reproduction in any medium or format, as long as you give appropriate credit to the original author(s) and the source, 
provide a link to the Creative Commons licence, and indicate if changes were made. The images or other third party material in this article are included in the article's Creative Commons licence, unless indicated otherwise in a credit line to the material. If material is not included in the article's Creative Commons licence and your intended use is not permitted by statutory regulation or exceeds the permitted use, you will need to obtain permission directly from the copyright holder. To view a copy of this licence, visit http://creativecommons.org/licenses/by/4.0/.

\section{References}

1. Hempelmann JA, Lockwood CM, Konnick EQ, Schweizer MT, Antonarakis ES, Lotan TL, Montgomery B, Nelson PS, Klemfuss N, Salipante SJ, Pritchard CC Microsatellite instability in prostate cancer by PCR or next-generation sequencing. J Immunother Cancer. 2018;6(1):29.

2. Sahnane N, Furlan D, Monti M, Romualdi C, Vanoli A, Vicari E, Solcia E, Capella C, Sessa F, la Rosa S Microsatellite unstable gastrointestinal neuroendocrine carcinomas: a new clinicopathologic entity. Endocr Relat Cancer. 2015;22(1):35-45.

3. Stelow EB, Moskaluk CA, Mills SE. The mismatch repair protein status of colorectal small cell neuroendocrine carcinomas. Am J Surg Pathol. 2006;30(11):1401-1404.

4. Olevian DC, Nikiforova MN, Chiosea S, Sun W, Bahary N, Kuan SF, Pai RK Colorectal poorly differentiated neuroendocrine carcinomas frequently exhibit BRAF mutations and are associated with poor overall survival. Hum Pathol. 2016;49:124-134.

5. Furlan D, Sahnane N, Mazzoni M, Pastorino R, Carnevali I, Stefanoli M, Ferretti A, Chiaravalli AM, la Rosa S, Capella C Diagnostic utility of MS-MLPA in DNA methylation profiling of adenocarcinomas and neuroendocrine carcinomas of the colon-rectum. Virchows Arch. 2013;462(1):47-56.

6. La Rosa S, Marando A, Furlan D, Sahnane N, Capella C. Colorectal poorly differentiated neuroendocrine carcinomas and mixed adenoneuroendocrine carcinomas: insights into the diagnostic immunophenotype, assessment of methylation profile, and search for prognostic markers. Am J Surg Pathol. 2012;36(4):601-611.

7. House MG, Herman JG, Guo MZ, Hooker CM, Schulick RD, Cameron JL, et al. Prognostic value of hMLH1 methylation and microsatellite instability in pancreatic endocrine neoplasms. Surgery. 2003;134(6):902-908; discussion 9.

8. Mei M, Deng D, Liu TH, Sang XT, Lu X, Xiang HD, Zhou J, Wu $\mathrm{H}$, Yang Y, Chen J, Lu CM, Chen YJ Clinical implications of microsatellite instability and MLH1 gene inactivation in sporadic insulinomas. J Clin Endocrinol Metab. 2009;94(9):3448-3457.

9. Joost P, Veurink N, Holck S, Klarskov L, Bojesen A, Harbo M, et al. Heterogenous mismatch-repair status in colorectal cancer. Diagn Pathol. 2014;9:126.

10. Chapusot C, Martin L, Bouvier AM, Bonithon-Kopp C, EcarnotLaubriet A, Rageot D, Ponnelle T, Laurent Puig P, Faivre J, Piard F Microsatellite instability and intratumoural heterogeneity in 100 right-sided sporadic colon carcinomas. Br J Cancer. 2002;87(4): 400-404.

11. Watson N, Grieu F, Morris M, Harvey J, Stewart C, Schofield L, Goldblatt J, Iacopetta B Heterogeneous staining for mismatch repair proteins during population-based prescreening for hereditary nonpolyposis colorectal cancer. J Mol Diagn. 2007;9(4):472-478.

12. Watkins JC, Nucci MR, Ritterhouse LL, Howitt BE, Sholl LM. Unusual Mismatch Repair Immunohistochemical Patterns in Endometrial Carcinoma. Am J Surg Pathol. 2016;40(7):909-916.

13. Pai RK, Plesec TP, Abdul-Karim FW, Yang B, Marquard J, Shadrach B, Roma AR Abrupt loss of MLH1 and PMS2 expression in endometrial carcinoma: molecular and morphologic analysis of 6 cases. Am J Surg Pathol. 2015;39(7):993-999.

14. Kononen J, Bubendorf L, Kallioniemi A, Barlund M, Schraml P, Leighton S, et al. Tissue microarrays for high-throughput molecular profiling of tumor specimens. Nat Med. 1998;4(7):844-847.

15. Tang LH, Basturk O, Sue JJ, Klimstra DS. A Practical Approach to the Classification of WHO Grade 3 (G3) Well-differentiated Neuroendocrine Tumor (WD-NET) and Poorly Differentiated Neuroendocrine Carcinoma (PD-NEC) of the Pancreas. Am J Surg Pathol. 2016;40(9):1192-1202.

16. Boland CR, Thibodeau SN, Hamilton SR, Sidransky D, Eshleman JR, Burt RW, et al. A National Cancer Institute Workshop on Microsatellite Instability for cancer detection and familial predisposition: development of international criteria for the determination of microsatellite instability in colorectal cancer. Cancer Res. 1998;58(22):5248-5257.

17. Hinsch A, Brolund M, Hube-Magg C, Kluth M, Simon R, MollerKoop C, et al. Immunohistochemically detected IDH1(R132H) mutation is rare and mostly heterogeneous in prostate cancer. World $\mathrm{J}$ Urol. 2018;36(6):877-882.

18. Simon R, Panussis S, Maurer R, Spichtin H, Glatz K, Tapia C, Mirlacher M, Rufle A, Torhorst J, Sauter G KIT (CD117)-positive breast cancers are infrequent and lack KIT gene mutations. Clin Cancer Res. 2004;10(1 Pt 1):178-183.

19. Pocrnich CE, Ramalingam P, Euscher ED, Malpica A. Neuroendocrine Carcinoma of the Endometrium: A Clinicopathologic Study of 25 Cases. Am J Surg Pathol. 2016;40(5):577-586.

20. Thibodeau SN, Bren G, Schaid D. Microsatellite instability in cancer of the proximal colon. Science. 1993;260(5109):816-819.

21. Chung HC, Lopez-Martin JA, Kao SC-H, Miller WH, Ros W, Gao $\mathrm{B}$, et al. Phase 2 study of pembrolizumab in advanced small-cell lung cancer (SCLC): KEYNOTE-158. J Clin Oncol. 2018;36(15 suppl):8506.

22. Warth A, Korner S, Penzel R, Muley T, Dienemann H, Schirmacher $\mathrm{P}$, et al. Microsatellite instability in pulmonary adenocarcinomas: a comprehensive study of 480 cases. Virchows Arch. 2016;468(3): 313-319.

23. Takamochi K, Takahashi F, Suehara Y, Sato E, Kohsaka S, Hayashi T, Kitano S, Uneno T, Kojima S, Takeuchi K, Mano H, Suzuki K DNA mismatch repair deficiency in surgically resected lung adenocarcinoma: Microsatellite instability analysis using the Promega panel. Lung Cancer. 2017;110:26-31.

24. Vanderwalde A, Spetzler D, Xiao N, Gatalica Z, Marshall J. Microsatellite instability status determined by next-generation sequencing and compared with PD-L1 and tumor mutational burden in 11,348 patients. Cancer Med. 2018;7(3):746-756.

25. Cortes-Ciriano I, Lee S, Park WY, Kim TM, Park PJ. A molecular portrait of microsatellite instability across multiple cancers. Nat Commun. 2017;8:15180.

26. Le DT, Durham JN, Smith KN, Wang H, Bartlett BR, Aulakh LK, et al. Mismatch repair deficiency predicts response of solid tumors to PD-1 blockade. Science. 2017;357(6349):409-413.

27. Sorbye H, Welin S, Langer SW, Vestermark LW, Holt N, Osterlund P, Dueland S, Hofsli E, Guren MG, Ohrling K, Birkemeyer E, Thiis-Evensen E, Biagini M, Gronbaek H, Soveri LM, Olsen IH, Federspiel B, Assmus J, Janson ET, Knigge U Predictive and prognostic factors for treatment and survival in 305 patients with advanced gastrointestinal neuroendocrine carcinoma (WHO G3): the NORDIC NEC study. Ann Oncol. 2013;24(1):152-160.

28. Mitsuhashi K, Yamamoto I, Kurihara H, Kanno S, Ito M, Igarashi H, Ishigami K, Sukawa Y, Tachibana M, Takahashi H, Tokino T, Maruyama R, Suzuki H, Imai K, Shinomura Y, Yamamoto H, Nosho K Analysis of the molecular features of rectal carcinoid tumors to identify new biomarkers that predict biological malignancy. Oncotarget. 2015;6(26):22114-22125. 
29. Kidd M, Eick G, Shapiro MD, Camp RL, Mane SM, Modlin IM. Microsatellite instability and gene mutations in transforming growth factor-beta type II receptor are absent in small bowel carcinoid tumors. Cancer. 2005;103(2):229-236.

30. Ghimenti C, Lonobile A, Campani D, Bevilacqua G, Caligo MA. Microsatellite instability and allelic losses in neuroendocrine tumors of the gastro-entero-pancreatic system. Int $\mathrm{J}$ Oncol. 1999;15(2):361-366.

31. Arnold CN, Sosnowski A, Blum HE. Analysis of molecular pathways in neuroendocrine cancers of the gastroenteropancreatic system. Ann N Y Acad Sci. 2004;1014:218-219.

32. Arnold CN, Nagasaka T, Goel A, Scharf I, Grabowski P, Sosnowski A, Schmitt-Gräff A, Boland CR, Arnold R, Blum HE Molecular characteristics and predictors of survival in patients with malignant neuroendocrine tumors. Int J Cancer. 2008;123(7):1556-1564.

33. Arnason T, Sapp HL, Rayson D, Barnes PJ, Drewniak M, Nassar BA, Huang WY Loss of expression of DNA mismatch repair proteins is rare in pancreatic and small intestinal neuroendocrine tumors. Arch Pathol Lab Med. 2011;135(12):1539-1544.

34. Sorscher S, Saroya B. A molecularly confirmed neuroendocrine tumor resulting from Lynch Syndrome. J Gastrointest Oncol. 2013;4(1):95-96.
35. Serracant Barrera A, Serra Pla S, Blazquez Mana CM, Salas RC, Garcia Monforte N, Bejarano Gonzalez N, et al. Pancreatic nonfunctioning neuroendocrine tumor: a new entity genetically related to Lynch syndrome. J Gastrointest Oncol. 2017;8(5):E73-EE9.

36. Fraune C, Simon R, Hoflmayer D, Moller K, Dum D, Buscheck F, et al. High homogeneity of mismatch repair deficiency in advanced prostate cancer. Virchows Arch. 2019.

37. Fraune C, Rosebrock J, Simon R, Hube-Magg C, MakrypidiFraune G, Kluth M, et al. High homogeneity of MMR deficiency in ovarian cancer. Gynecol Oncol. 2020.

38. Schuster-Bockler B, Lehner B. Chromatin organization is a major influence on regional mutation rates in human cancer cells. Nature. 2012;488(7412):504-507.

39. Supek F, Lehner B. Differential DNA mismatch repair underlies mutation rate variation across the human genome. Nature. 2015;521(7550):81-84.

Publisher's Note Springer Nature remains neutral with regard to jurisdictional claims in published maps and institutional affiliations. 